\title{
La retórica del miedo como estrategia política. El plebiscito por la paz en Colombia*
}

\author{
Luz Margarita Cardona Zuleta** \\ César Augusto Londoño Álvarez****
}

Universidad Nacional de Colombia

\section{Resumen}

El presente artículo analiza los discursos de los líderes políticos más representativos de la campaña del plebiscito por la paz en Colombia, el líder del Sí, presidente Juan Manuel Santos, y el representante más visible de la campaña por el No, el líder del partido político Centro Democrático, expresidente y senador Álvaro Uribe Vélez, quien encabezó durante más de cinco años una oposición frontal al gobierno y a las negociones de paz. En estos discursos se busca identificar el uso de las emociones - de los componentes no racionales

\footnotetext{
*Artículo recibido: 29 de diciembre de 2017 / Aceptado: 25 de abril de 2018 / Modificado: 07 de mayo de 2018. El artículo es resultado del proyecto de investigación "Democracia, crisis de representación y liderazgo político. Colombia 2002-2016” que adelanta la profesora Luz Margarita Cardona Zuleta desde 2016 y de la tesis que desarrolla en la actualidad el estudiante, César Augusto Londoño Álvarez, de la maestría en Estudios Políticos de la Universidad Nacional de Colombia (Medellín, Colombia), "Democracia deliberativa, ciudadanía y derechos fundamentales de las víctimas del conflicto armado en Colombia 2004-2015”, bajo la dirección de la profesora Luz Margarita Cardona Zuleta.

***Doctora en Ciencia Política por Universidad Nacional de Rosario (Rosario, Argentina). Profesora asociada de la Universidad Nacional de Colombia (Medellín, Colombia). Últimas publicaciones: La culebra sigue viva: miedo y política. El ascenso de Álvaro Uribe al poder presidencial en Colombia (2002-2010). Medellín: Editorial Universidad Nacional de Colombia, 2016 y Actores Políticos y Sociales en el Acto Legislativo para la Paz. Un análisis desde la metodología stakeholders". En G.E. Pacheco, G.F. Niño Contreras, J.A. Escobar Solano, M.A. Gómez González, L. Muñoz Meneses y K.F. Henao Martínez (Comps.), Procesos legislativos y ordenamiento constitucional: abordajes teóricos (pp. 272-284). Bogotá: República de Colombia - Senado de la República - Centro De Investigaciones Y Altos Estudios Legislativos (CAEL), 2016. Correo electrónico: Imcardona@unal.edu.co (iD) https://orcid.org/0000-0003-4749-4012

****Abogado, especialista en Derecho Constitucional de la Universidad de Antioquia (Medellín, Colombia) y candidato a Magíster en Estudios Políticos por la Universidad Nacional de Colombia (Medellín, Colombia). Docente de catedra de la Facultad de Derecho y Ciencias Políticas de la Universidad de Antioquia (Medellín, Colombia) y miembro del área jurídica de la Fundación Forjando Futuros (Medellín, Colombia). Correo electrónico: cealondonoal@unal.edu.co iD) https://orcid.org/0000-0003-2897-9022
} 
de la política-, específicamente del miedo como elemento principal para influir en la decisión de los electores a favor del voto aprobatorio o desaprobatorio de los acuerdos de paz firmados en La Habana (Cuba), entre representantes del gobierno de Colombia y de las Fuerzas Armadas Revolucionarias de Colombia (FARC). Para lograr este propósito, se realizó el estudio de tres intervenciones del presidente Juan Manuel Santos y dos del expresidente Álvaro Uribe Vélez anteriores al domingo 2 de octubre de 2017, día de la votación, y una intervención del gerente del Comité Promotor Nacional por el No -y reconocido uribista-, Juan Carlos Vélez Uribe, posterior a la jornada electoral en cuestión. Para presentar esta confrontación discursiva, el artículo describe el contexto institucional y las reglas de juego que demarcaron la acción política de los principales actores de esta campaña sui géneris.

Palabras clave: acuerdo de paz, democracia, participación política, liderazgo, Colombia (Thesaurus); plebiscito (Autor).

\title{
The Rhetoric of Fear as a Political Strategy. The Plebiscite for Peace in Colombia
}

\begin{abstract}
This article analyzes the discourses of two political leaders during the campaigns before the peace referendum in Colombia. On one hand, the leader of the Yes-Campaign, and then-president Juan Manuel Santos. On the other hand, the most visible representative of the No-Campaign: the leader of the Democratic Centre political party, former president, and then-Senator Álvaro Uribe Vélez, who spearheaded a frontal opposition to the Government and to the peace negotiations for more than 5 years. This study seeks to identify the use of emotions -the non-rational component of politics- in their speeches and, more specifically, of fear as the main element used to influence the voters' stance -in favor or against-, regarding the Peace Agreements signed in Havana (Cuba) between representatives of the Government and the Fuerzas Armadas Revolucionarias de Colombia (FARC). In order to achieve this purpose, this study analyzed three interventions by President Juan Manuel Santos and two by Álvaro Uribe Vélez prior to polling day, October 2, 2017. It also analyzed one intervention after polling day by the Manager of the National No-Promoting Committee and recognized uribista, Juan Carlos Vélez Uribe. Then, contextualizing the discursive confrontation, this article describes the institutional context and the rules that guided the political actions of the major players in this sui generis campaign.
\end{abstract}

Keywords: peace agreement, democracy, political participation, leadership, Colombia (Thesaurus); plebiscite (Author). 


\section{Introducción}

La elección del presidente Álvaro Uribe Vélez en el año 2002 y su reelección en 2006 ocurrieron como efecto del cansancio de un sector importante del electorado colombiano, debido al fracaso de los procesos de diálogo y negociación emprendidos con los principales grupos guerrilleros de izquierda, especialmente el "proceso de paz del Caguán” que inició el gobierno del presidente Andrés Pastrana Arango y la guerrilla de las Fuerzas Armadas Revolucionarias de Colombia (FARC)ํ․ Pero también, el éxito electoral del ex presidente Uribe Vélez y actual Senador del partido Centro Democrático se debe, entre otras consideraciones, a su capacidad de manipular hábilmente el miedo que existe entre un sector importante de la sociedad colombiana a las FARC y al proyecto político que representan, y que en el imaginario de muchos colombianos se asocia a los modelos socialistas encarnados en los gobiernos de los hermanos Castro en Cuba y en el socialismo del siglo XXI imperante en Venezuela (Cardona Zuleta, 2016).

En 2002, con el 54.51\% de los votos, fue electo el presidente Álvaro Uribe Vélez. Una vez en el cargo comenzó la implementación de la Política de Seguridad Democrática (PSD), propuesta de campaña y bandera de sus dos administraciones. Esta política tenía como objetivo principal el control de territorio nacional a través de la lucha frontal contra los grupos armados ilegales: grupos paramilitares, organizaciones para el tráfico de drogas ilícitas y guerrillas, no obstante, tanto en la estrategia militar, pero sobre todo en la estrategia discursiva de Uribe Vélez, las FARC fueron identificadas como el enemigo principal y destinatario de las más encendidas confrontaciones discursivas del entonces presidente (Cardona Zuleta, 2016).

La PSD despertó desconfianza en un sector importante de la sociedad civil organizada por los efectos perversos que pudiera tener en materia de violación a los derechos humanos, en el marco de una guerra irregular que se libró principalmente en sectores apartados del territorio nacional y donde los actores armados tienden a no distinguir suficientemente entre combatientes y población civil. Componentes de la "Estrategia Integral para Ganar la Guerra” como los soldados campesinos, las redes informantes y cooperantes, la política de recompensas a los informantes, aumentaban la sospecha (Redacción Semana, 2005). Sin embargo, la PSD también mejoró la percepción de seguridad entre los colombianos y reportó al presidente altos niveles de popularidad durante sus dos gobiernos.

1. Los llamados "diálogos del Caguán” entre el gobierno de Andrés Pastrana Arango y las FARC se iniciaron el 7 de enero de 1999 y culminaron después de múltiples desencuentros entre las partes, el 25 de febrero de 2002, cuando esa guerrilla desvío un avión comercial y secuestró al entonces senador de la República Jorge Eduardo Gechem Turbay (Palacio y Quintero 2002; Redacción El Tiempo, 2010). 
Para el año 2010, al término de su gestión, el presidente Uribe Vélez tenía un nivel de aprobación del 80\% (Redacción El País, 2010), y con esta popularidad ofreció su apoyo a su exministro de defensa Juan Manuel Santos, a quien confió el cuidado del éxito de su programa bandera, la PSD. Como candidato de Uribe Vélez, Santos ganó las elecciones en segunda vuelta, con el $69.05 \%$ del total de los votos, contra Antanas Mockus quien obtuvo el 27.52\%, y el voto en blanco el 3.41\% (Redacción Colombia. com, 2010). Una de las razones de su victoria radicó en la promesa de continuidad de la PSD, el mantenimiento de "[...] una presión incesante sobre los violentos, organizados en bandas criminales, grupos guerrilleros y terroristas" (Principales propuestas de Juan Manuel Santos, 2010).

Una vez posesionado en el cargo, el Presidente Juan Manuel Santos tomó una serie de decisiones que disgustaron al expresidente Uribe Vélez, en tanto este último consideró que contrariaban la PSD que Santos dijo defender durante la campaña. Una de estas medidas fue el restablecimiento de las relaciones diplomáticas con Venezuela, país gobernado en ese entonces por Hugo Chávez, quien fuera el principal opositor político de Uribe Vélez entre los gobiernos de la región andina ${ }^{2}$. Sumado a lo anterior, el 10 de junio de 2011 por iniciativa gubernamental, bajo el amparo del partido Liberal -uno de los principales opositores durante los ocho años de gobierno del Presidente Álvaro Uribe Vélez-se logró la expedición de la Ley 1448 de 2011, mediante la cual se reiteró la existencia de un conflicto armado interno en Colombia, declaración que estuvo ausente durante el gobierno de Uribe Vélez y que permitió discutir de nuevo sobre el estatus político de los grupos guerrilleros. Sin embargo, la ruptura definitiva entre Santos y Uribe vino por cuenta del anuncio presidencial de iniciar diálogos de paz con las FARC (Wallace, 2014).

El 26 agosto de 2012, el gobierno de Juan Manuel Santos y la guerrilla de las FARC firmaron en La Habana (Cuba) "el Acuerdo general para la terminación del conflicto y la construcción de una paz estable y duradera”, luego de seis meses de conversaciones secretas (Cronología del proceso de paz, 2014). El mismo mes, en la ciudad de Cartagena, el expresidente Álvaro Uribe Vélez informó a la opinión pública la existencia de dichos diálogos, los que presentó como innecesarios - ante la efectividad de la PSD que su gobierno mantuvo durante ocho años-y ventajosos para la guerrilla (Álvaro Uribe critica los diálogos de paz que adelanta el gobierno colombiano con las FARC, 2012).

2. Las relaciones diplomáticas de Colombia y Venezuela se rompieron luego de que el gobierno colombiano, en cabeza de Álvaro Uribe Vélez, denunciara a Hugo Chávez, su homólogo venezolano ante la Organización de Estados Americanos (OEA) por permitir la estadía y tránsito de grupos guerrilleros colombianos en su territorio (Fermín, 2012). 
Desde el momento en que se iniciaron los diálogos de paz, el presidente Santos prometió que sería el pueblo colombiano quien refrendaría lo pactado con las FARC en La Habana. Después de buscar distintas alternativas jurídicas y políticas, mediante la Ley Estatutaria $\mathrm{N}^{\circ} 1806$ del 24 de agosto de 2016, se autorizó la convocatoria al plebiscito, con una pregunta única y sólo dos posibles repuestas, aprobatoria o desaprobatoria, de lo acordado entre las partes (Congreso de la República de Colombia. Ley N 1806 de 2016).

El presente artículo analiza los discursos de los dos líderes políticos más representativos de la campaña por el voto a favor y el voto en contra del plebiscito por la paz en Colombia, Juan Manuel Santos y Álvaro Uribe Vélez, respectivamente. Este último, quien encabezó una oposición frontal contra la política de negociación para la finalización del conflicto armado con la guerrilla de las FARC. En sus intervenciones se identificó el uso de las emociones ${ }^{3}$-de los componentes no racionales de la política-, específicamente del miedo, para influir en la decisión del electorado en el proceso político que definía sobre la refrendación popular de los acuerdos firmados en La Habana (Cuba).

Para ello, se estudiaron tres intervenciones del presidente Juan Manuel Santos y dos del expresidente Álvaro Uribe Vélez, previas a la fecha de votación del referendo de 2017 y una intervención posterior, del gerente del Comité Promotor Nacional por el No, Juan Carlos Vélez Uribe.

Acorde con el objetivo propuesto, el artículo se divide en cuatro apartados. El primero describe el contexto institucional y las reglas de juego que demarcaron la acción política de los principales actores de esta campaña sui géneris. En el segundo, se analiza la utilización de las emociones, específicamente el uso instrumental que los actores políticos hicieron del miedo para influir en la decisión de voto de los electores, y que desplazó al dialogo racional y a la deliberación, aspectos tan valorados por la tradición del pensamiento político moderno.

En el tercer apartado, a partir del análisis del discurso pos-plebiscito, se insiste en el planteamiento acerca de cómo la discusión no se centró en los contenidos de los acuerdos firmados, ni en propuestas alternativas, mejores o razonables a estos acuerdos, sino que continuó enfocada en agitar los miedos frente a dos escenarios que resultarían catastróficos para el país: la no aprobación de los acuerdos significaría para el gobierno la "vuelta a la guerra” (Redacción El Heraldo.co, 2016), no obstante que este grupo insurgente insistiera en que si ganaba el No en el plebiscito no volverían a la guerra (Redacción Paz, 2016); para los promotores del No la aprobación de los acuerdos representaría la adopción del llamado modelo "castro-chavista", en la particular versión del ex Presidente Uribe (Colprensa, 2015). En el cuarto apartado, se enuncia algunas conclusiones del artículo.

3. Sobre el rol de los componentes emocionales en la política, se puede consultar Robin (2009) y Botero (2001). 


\section{Campaña política del plebiscito, una carrera contra el tiempo}

El Acto Legislativo 01 del 31 de julio de 2012 fue el instrumento constitucional que le dio vía libre al gobierno nacional, para adoptar los mecanismos de justicia transicional y allanar el camino para los procesos de negociación con los grupos armados insurgentes. Esta herramienta jurídica se encuadró en el respeto de los derechos de las víctimas a la verdad, la justicia, la reparación y la garantía de no repetición; y en el cumplimiento por parte de los actores que se sometieran a esta justicia, de los compromisos adquiridos, entre los que se cuentan el abandono de la lucha armada, de toda actuación de carácter criminal y nexo con organizaciones criminales. Componente integral de estos mecanismos era la Ley 1448 de 2011, Ley de víctimas y restitución de tierras, en tanto consagró unas garantías mínimas de reparación, rehabilitación y restitución a favor de las víctimas del conflicto armado colombiano. Estas acciones del Estado no fueron concertadas con la guerrilla de las FARC.

Con este precedente, durante el desarrollo y avance del proceso de negociación, el gobierno colombiano y la guerrilla de las FARC estructuraron unos acuerdos en temas referentes a la reforma rural integral, apertura del sistema de participación política ${ }^{4}$, cese al fuego y reincorporación a la vida civil de los desmovilizados, drogas ilícitas, cultivo de uso ilícito, derechos de las víctimas y justicia transicional, entre otros. Desde el comienzo de los diálogos, el Presidente prometió que los acuerdos serían refrendados por el pueblo ${ }^{5}$, para dotarlos de una fuerte base de legitimidad democrática que les permitiera perdurar en el tiempo, pese a vaivenes de los ciclos electorales y a la postura política de futuros gobiernos ${ }^{6}$.

En un primer momento, se expidió la Ley 1745 del 26 de diciembre de 2014 "Por medio de la cual se dictan las reglas para el desarrollo de referendos constitucionales con ocasión de un acuerdo final para la terminación del conflicto armado", y se establecieron las garantías de participación de los distintos actores políticos dentro de una contienda electoral de estas características. Posteriormente, y ante las dificultades

\footnotetext{
4. Estos dos primeros componentes pueden considerarse como desarrollo de aquello que en la doctrina constitucional se denomina la democracia sustancial y la democracia formal, la primera hace referencia a la participación de los sujetos en los beneficios que se generan en el ámbito social, económico y cultural. Respecto a la democracia formal, ésta no sólo se expresa en los procedimientos de participación democrática, se extiende también a las garantías políticas ofrecidas a los sujetos políticos excluidos de la participación del poder político y la extensión del modelo democrático de toma de decisión más allá del ámbito de la política. Véase su consagración normativa en el artículo $2^{\circ}$ de la Constitución Política de Colombia y su desarrollo teórico en Ferrajoli (2009, p. 858) y Bobbio (2005, p. 65). 5. Sobre la promesa elevada por el Presidente Juan Manuel Santos el 22 de agosto de 2013 de refrendar los eventuales acuerdos logrados con la guerrilla de las FARC (Redacción Política, 2013).

6. Voceros de otras instituciones del poder público como el otrora fiscal general de la nación Eduardo Montealegre, sostuvieron que el plebiscito no era el mecanismo adecuado para la refrendación de los acuerdos de paz (Isaza Giraldo, 2016).
} 
técnicas que implicaba realizar un referendo como mecanismo de refrendación de los acuerdos logrados entre las partes durante el proceso de paz $^{7}$, mediante la Ley Estatutaria 1806 del 24 de agosto de 2016, "Por medio de la cual se regula el plebiscito para la refrendación del acuerdo final para la terminación del conflicto y la construcción de una paz estable y duradera”, se dio vía libre a la convocatoria al plebiscito, para que el electorado en respuesta a una pregunta única, respondiera si aprobaba o desaprobaba los acuerdos pactados por el gobierno nacional y la guerrilla de las FARC.

La ley establecía un procedimiento que implicaba que el presidente de la República debía informar al Congreso sobre su intención de realizar el plebiscito, órgano que dispondría de un mes para pronunciarse al respecto. Surtido este trámite, la presidencia realizaría la consulta al electorado después del mes siguiente al informe presentado ante el Congreso, y antes de los cuatro meses de éste. Adicionalmente, la ley de convocatoria estaba pendiente de revisión de constitucionalidad por parte de la Corte Constitucional.

El informe se radicó en el Congreso el día 29 de agosto de 2016 y fue aprobado en menos de cinco horas (Redacción Semana, 2016), tiempo después del cual el Ejecutivo procedió a realizar la convocatoria al plebiscito mediante el Decreto 1391 del 30 de agosto de 2016. La fecha del plebiscito sería el 2 de octubre de 2016, es decir, un mes y seis días después de fijado el mecanismo de refrendación. Éste sería el término con el cual contarían oficialmente los actores políticos para realizar la campaña en favor o en contra de los acuerdos. Aunado a ello, los electores tendrían un mes y doce días para informarse sobre el contenido definitivo de lo pactado, que se dio a conocer el 24 de agosto de 2016 y se plasmó en un documento de 297 páginas, imposibles de leer y entender en este corto lapso de tiempo por el ciudadano del común convocado a las urnas ${ }^{8}$.

La celeridad en la celebración del plebiscito constitucional plantea el interrogante respecto a si dicha premura estuvo determinada por la necesidad de los agentes plenipotenciarios que representaban al gobierno nacional y los delegados de las FARC de no incurrir en inhabilidades constitucionales y legales ante unas eventuales elecciones presidenciales ${ }^{9}$.

En razón del apuro en el desarrollo de este proceso, las reglas del juego para la celebración de este acto de manifestación del poder soberano popular no quedaron muy

\footnotetext{
7. Técnicamente y de acuerdo con los parámetros establecidos en los artículos 41 y 42 de la Ley 134 de 1994 , implicaba realizar una consulta de cada uno de los puntos acordados en La Habana, transformándolo en un instrumento engorroso y de difícil acceso y comprensión para la ciudadanía (Redacción El Tiempo, 2015). 8. Se aclara que desde el 26 de mayo de 2013 se venían dando informes parciales sobre los puntos acordados. Véanse los distintos comunicados en la página: http://www.altocomisionadoparalapaz.gov.co/ mesadeconversaciones/index.html

9. Intenciones que se manifestaron posteriormente por parte de Humberto de la Calle y Rodrigo Londoño.
} 
claras y tuvieron que ser precisadas por medio de las vías judiciales constitucionales, procedimiento poco coherente en los contextos democráticos, donde la regla general de expresión y delimitación de la voluntad soberana debe ser la Constitución y la ley, no la jurisprudencia de los órganos especializados. Un ejemplo de esta falta de claridad lo constituyó la propuesta de incorporar al cuerpo de la Constitución el texto acordado en La Habana, en caso de resultar aprobado en la consulta popular prevista ${ }^{10}$.

\section{Las campañas del Sí y el No, el miedo, único consenso en un escenario de polarización política}

\section{Los discursos de los actores durante el proceso de negociación de los acuerdos, la imposibilidad de un diálogo racional}

En este apartado se analizan las intervenciones del gobierno nacional y del partido político Centro Democrático sobre el proceso de paz en curso, hasta el sometimiento del acuerdo al veredicto popular en el plebiscito celebrado el 2 de octubre de 2016. Sin desconocer que existieron otras voces de apoyo por el Sí externas al gobierno -la mayoría de los medios de comunicación, la academia, los gremios empresariales reunidos en torno al Consejo Gremial y otros sectores de la sociedad civil organizada-, el análisis se centra en la postura del Ejecutivo por tratarse de una iniciativa gubernamental que contaba con todos los recursos del poder presidencial para llevar a buen término un proyecto como el plebiscito. Frente a las posturas del No, el análisis se enfoca en los pronunciamientos emitidos por el Senador Álvaro Uribe Vélez, líder del partido político Centro Democrático y figura más visible de los sectores de opinión que confluyeron en torno a la campaña del $\mathrm{No}^{11}$-el partido del expresidente, sectores del partido conservador y grupos cristianos-.

En entrevista con la periodista Diana Calderón en la emisora Caracol Radio el 21 de agosto de 2012 (Le pido al Gobierno que diga si es verdad que están negociando un proceso de paz en Cuba: Álvaro Uribe, 2012), cuando aún se discutía la existencia de los diálogos entre el gobierno y las FARC, el expresidente Uribe Vélez manifestó una visión negativa frente a esta posibilidad. En primer lugar, expresó que cualquier interlocutor que

10. Por cuanto solo es vinculante para el presidente de la república. Otro elemento no claro era la forma de participación de los funcionarios públicos (Corte Constitucional de Colombia, Sentencia C-379 del 18 de julio de 2016, Magistrado Ponente Dr. Luis Ernesto Vargas Silva).

11. Como lo indicara Morelo (2016) y después de un análisis de los resultados electorales del 2 de octubre de 2016, el uribismo fue determinante para la victoria del No, conclusión que extrae después de estudiar y comparar los resultados de las elecciones presidenciales del año 2014, respecto a los resultados del plebiscito por la paz. 
se "siente" a dialogar o a negociar con un grupo guerrillero -terrorista- se equilibra, o mejor se rebaja a su misma condición. En segundo lugar, desnaturalizó el concepto mismo de negociación, donde las partes que tienen intereses contrapuestos dialogan para construir conjuntamente un acuerdo. Para el expresidente, el gobierno debía acordar con las FARC únicamente los términos de su rendición, del sometimiento a la justicia. El expresidente en su discurso se centró sobre todos en los criterios de justicia retributiva:

¿En qué radican esas preocupaciones? [...] el Gobierno ha venido dando señales de preferir una negociación con las Farc, que la política de seguridad, una negociación debería ser un sometimiento a la justicia cuando prevalezca la política de seguridad, cuando prime la política de seguridad y haya producido sus efectos. (Le pido al Gobierno que diga si es verdad que están negociando un proceso de paz en Cuba: Álvaro Uribe, 2012)

Para él, cualquier proceso de negociación o desmovilización con grupos armados al margen de la ley es ilegitimo políticamente y contrario a los postulados constitucionales del principio democrático. Indicó al mismo tiempo que el único plan viable es un proceso de confrontación efectiva contra estos grupos, que los lleve hasta tal punto de debilidad militar ${ }^{12}$, anulando cualquier otra alternativa distinta al sometimiento del imperio de la ley y la justicia estatal:

¿Qué se puede negociar con ellos? Elegibilidad como lo dice el marco para la paz, muy grave, porque en una democracia como esta es claro que aquellos responsables de delitos de lesa humanidad, de delitos atroces, de graves violaciones al Derecho Internacional Humanitario, etc., no pueden ser elegibles, aquí les están abriendo la compuerta para la elegibilidad, eso es una bofetada a la democracia. ¿Qué se puede negociar con ellos? Esta es una democracia respetable, aquí no hay que negociar una apertura democrática con ellos, este país la ha hecho solito, desde hace mucho rato. Lo único que hay para negociar con el terrorismo es su sometimiento a la justicia, y los beneficios en materia de recorte de penas, que en una política de sometimiento se puedan ofrecer, como está en la ley de Justicia, Paz y Reparación, que le hace mucho daño a la democracia cuando a los terroristas se les ofrece posibilidades de elegibilidad a cargos de elección popular. Se le hace mucho daño a la democracia cuando se pretende negociar con terroristas la agenda social, económica o política del país. Esa agenda hay que discutirla diariamente en las instituciones de la democracia, no con los terroristas. (Le pido al Gobierno que diga si es verdad que están negociando un proceso de paz en Cuba: Álvaro Uribe, 2012)

En la visión del expresidente, cualquier posibilidad de negociación con la guerrilla debilitaba la PSD y se convertía en un factor de desmotivación para las Fuerzas Armadas, de restricción de la iniciativa militar; y en contra partida, los únicos beneficiados de

12. No reconociendo sus manifestaciones políticas. 
estos procesos serían los grupos guerrilleros, que se podían fortalecer en su actividad criminal y militar. Por esta razón, la única alternativa política que tenía su sucesor era retomar los hilos de la PSD, pretendiendo, el ex Presidente, establecer las prioridades de la agenda de Santos y/o gobernar a través de interpuestos ${ }^{13}$ :

\begin{abstract}
Diana Calderón: ¿Usted en qué cree que pueden terminar unas conversaciones de paz con las Farc? Ex Presidente Álvaro Uribe: Hoy lo único que ha logrado el Gobierno con eso, en los últimos dos años, es sumarle un grave factor de desmotivación a las Fuerzas Armadas y permitir que estos bandidos de las guerrillas, de las Bandas Criminales, todos auspiciados por el narcotráfico, estén creciendo su capacidad criminal y haciéndole mucho daño al país porque siempre que hay que hablar del tema, uno no puede hablar de la seguridad como algo aislado, la seguridad es una fuente de recursos, un valor democrático. Sin seguridad no hay inversión, sin inversión no hay política social, por eso siempre he hablado de ese equilibrio, de ese centro, que se integra entre la seguridad, la política de inversión y la política social, son inseparables. (Le pido al Gobierno que diga si es verdad que están negociando un proceso de paz en Cuba: Álvaro Uribe, 2012)
\end{abstract}

Distintos analistas de medios han insistido en las habilidades de comunicador que tiene el expresidente y hoy Senador (Gómez Giraldo, 2005). En efecto, el discurso de Uribe Vélez gira en torno a unas ideas básicas de fácil recordación por el público: seguridad, orden, lucha contra el terrorismo y confianza inversionista, como lo hizo en las campañas presidenciales del 2002 y del 2006 y durante los ocho años de gobierno. Pero otra habilidad reconocida del expresidente es la capacidad de manipular el miedo para obtener objetivos políticos. Al insistir constantemente en el abandono de PSD - por parte de su sucesor- va dibujando un horizonte en el que se vislumbra el retorno a las condiciones de inseguridad del pasado, específicamente a aquella durante el gobierno de Andrés Pastrana, donde actores armados de distinto tipo imponían sus leyes en territorios despojados de la presencia de la fuerza pública. Con un discurso duro contra los grupos armados, especialmente contra la guerrilla, se dio el ascenso de Álvaro Uribe Vélez al poder presidencial en Colombia en 2002 (Cardona Zuleta, 2016).

Posteriormente, en alocución del 4 de septiembre de 2012, el presidente Juan Manuel Santos reiteró que en efecto se realizaban acercamientos con la guerrilla de las FARC para verificar si existía disposición para iniciar un proceso de diálogo. En esta alocución, el presidente indicó en primer lugar, que los acercamientos con la guerrilla de las FARC

13. Sobre el deseo de permanecer en el poder o gobernar a través de interpuestos, elegir a los sucesores, familiares, o amigos confiables para que los releven en el poder, (Alcántara Saéz, 2017). 
se daban como consecuencia de retomar unos canales que habían sido establecidos en el gobierno anterior:

El acuerdo lleva el nombre de "Acuerdo General para la Terminación del Conflicto", y tiene su origen en unos canales que había establecido el gobierno anterior y que nosotros retomamos y continuamos. (Santos, 2012)

En esta intervención, Santos agregó que no había una ruptura con la PSD del expresidente Uribe Vélez, puesto que esta alternativa también había sido considerada por su predecesor. Además, con ello respondió a la crítica lanzada por el expresidente en la intervención del 21 de agosto de 2012 donde consideró que ningún gobierno debería negociar con grupos "narcoterroristas" a menos que se equilibrara con ellos.

En segundo lugar, el discurso del presidente marcó una clara diferencia con su antecesor, en el sentido de afirmar que el gobierno actual estaba abierto a explorar otras alternativas para la terminación del conflicto, entre ellas, sentarse a concertar con las FARC las condiciones y compromisos que las partes asumirían para dar por terminada la guerra:

En ellas se construyó una visión compartida del fin del conflicto y se acordaron el propósito, la agenda y las reglas de juego de un proceso que debe ser serio, digno, realista y eficaz.

$[\ldots]$

Cualquier gobernante responsable sabe que no puede dejar pasar una posibilidad como ésta de acabar con el conflicto. (Santos, 2012)

De este modo, el presidente se alejó de la perspectiva de la negociación como mero sometimiento del enemigo -concepción dominante en el gobierno de Uribe Vélez-y abrió una vez más la posibilidad a la política mediante el reconocimiento del otro y la búsqueda de unos acuerdos posibles.

Además, en este discurso, el presidente respondió a otras críticas de su antecesor, sin confrontarlo y así eludir el riesgo de un enfrentamiento directo ${ }^{14}$. Planteó la necesidad de continuar con la reparación a las víctimas del conflicto armado, política que ya había iniciado el gobierno anterior con el Decreto 1290 de 2008 y que fue profundizada por el gobierno Santos mediante la Ley 1448 de 2011, reglamentada mediante el Decreto

14. Hay que recordar la enorme popularidad que Uribe Vélez mantiene, incluso como expresidente, en un sector del electorado, y las desventajas, en términos de popularidad, que podría representar para el presidente Santos un enfrentamiento directo con su antecesor. 
4800 de 2011. Esta ley estableció un procedimiento judicial expedito para la restitución de las tierras a quienes se vieron obligados a abandonarlas como consecuencia del conflicto armado o fueron despojados por alguno de los actores del conflicto. Sin embargo, y para resaltar la necesidad de los acuerdos de paz, el presidente Santos planteó la necesidad de un marco de reparación que fuera más allá de la justicia retributiva de castigo a los culpables de los hechos victimizantes y estableciendo un acuerdo que permitiera satisfacer los derechos a la verdad, la justica, la reparación y la garantía de no repetición:

¡Y eso sí que lo entienden los millones de víctimas!

¿Cuántos colombianos no han sufrido el conflicto en carne propia?

¿Cuántos colombianos no tienen un familiar que haya sido víctima de la violencia? (Santos, 2012)

Asimismo, en un mensaje a los escépticos del proceso de paz, por el fracaso de los diálogos de paz promovidos en gobiernos anteriores, específicamente los "diálogos del Caguán”, recordó a los electores que ya existían experiencias de procesos de diálogo, donde se había concertado entre las partes la cesación del conflicto armado, y por las vías de la democracia, otrora excombatientes ocupaban cargos de elección popular, incluso siendo jefes de gobierno en sus respectivos países: ${ }^{15}$

Ningún país de la región lo tolera, y en varios hay gobernantes que dejaron atrás la lucha armada y optaron por el camino de la democracia. (Santos, 2012)

Frente a la desmotivación de las fuerzas militares que acarrearía el proceso de paz -argumento muchas veces repetido por Uribe Vélez-, el presidente Santos reiteró que la actual negociación se dio gracias a la acción efectiva de la fuerza pública que había debilitado militarmente a los grupos armados y le había permitido al Estado recuperar el control del territorio nacional:

\footnotetext{
Hoy podemos hablar de paz gracias a los éxitos de nuestras Fuerzas Militares y de Policía, y gracias a la creciente presencia del Estado en todo el territorio nacional.

Hoy podemos hablar de paz gracias al esfuerzo diario de nuestros soldados y de nuestros policías, a quienes en este momento quiero rendir un homenaje.

Yo sé lo que es la guerra porque fui Ministro de Defensa en un momento crucial y conocí de primera mano el sacrificio de nuestros hombres.
}

15. Posiblemente haciendo referencia al expresidente uruguayo José Alberto Mujica Cordano. 
Hoy podemos hablar de paz porque la visión de mi gobierno es una visión integral: NO combatimos por combatir; combatimos para alcanzar la paz.

$[\ldots]$

Este acuerdo es diferente porque no tiene despejes de territorio y porque no hay cese de operaciones militares. (Santos, 2012)

En la lógica de desvirtuar el argumento de la desmoralización de la fuerza pública, el presidente Santos insistió que en este proceso de paz no se había definido bilateralmente un cese al fuego y no se habían establecido zonas de despeje vedadas a la fuerza pública. Advirtió también que de no avanzar el proceso o de llegar a un punto de no acuerdo, la mesa de negociación sería levantada.

Tanto en el discurso del expresidente Uribe Vélez, como en el del presidente Santos, se advierte que sus emisores acuden tanto a componentes racionales de la política como a los no racionales. El presidente Santos buscó, a través de argumentos jurídicos y políticos, convencer a la opinión pública sobre las bondades de un proceso de paz que puede tramitarse sin socavar las bases del Estado de derecho, apela, así mismo, a despertar entre los colombianos la emoción que suscitaría la esperanza de una Colombia en paz; pero donde el presidente Santos ve posibilidades políticas y jurídicas, el expresidente Uribe Vélez ve riesgos no sólo para la seguridad de los colombianos, sino para la vigencia misma del Estado de derecho. Pero como bien señala María de los Ángeles Yannuzzi, con la irrupción de las masas en el espacio público, la política adquiere visos de irracionalidad, que la distancian del ideal iluminista del diálogo como búsqueda de la verdad, del argumento mejor, ideal tan valorado por los teóricos del pensamiento político moderno (Yannuzzi, 2007).

Para el gobierno nacional fue más difícil generar entre la opinión pública un sentimiento mayoritario de esperanza en torno a la propuesta de paz negociada y contrarrestar los efectos simbólicos de un discurso que tuvo como emisor a un líder carismático que durante ocho años ondeó la bandera de la derrota militar de la guerrilla y promovió entre los colombianos el odio hacia esa organización ${ }^{16}$. Como sostiene Fabio López de la Roche, durante sus dos gobiernos Uribe Vélez no sólo obtuvo resultados significativos en materia de seguridad, especialmente en su lucha contra la guerrilla, "Uribe Vélez, enarboló y socializó entre los colombianos con indudable éxito un poderoso sentimiento de 'nacionalismo antifariano'”

16. No hay que olvidar que la contienda electoral del plebiscito fue bastante reñida. El Sí obtuvo el $49.78 \%$ (6.377.482 votos) y el No el 50.21\% (6.431.376 votos), los demás fueron votos nulos y votos no marcados, para un total de votos válidos de 12.808.858. El resultado electoral mostró el grado de polarización que alcanzó la sociedad colombiana en torno a los acuerdos pactados entre el gobierno y la guerrilla de las FARC (Registraduría Nacional del Estado Civil, 2016). 
(López de la Roche, 2014, p. 545), para López de la Roche, con la práctica del secuestro, “La guerrilla terminó tendiéndose así mismo una verdadera 'trampa afectiva' que enajenó cualquier visión positiva que la sociedad colombiana - sobre todo en amplias mayorías urbanas- pudiese tener acerca de esa organización” (López de la Roche, 2014, p. 546).

\section{Intervenciones en la etapa final de los diálogos de paz de La Habana}

Para el año 2016, en la recta final del proceso de diálogo entre el gobierno de Juan Manuel Santos y la guerrilla de las FARC, los discursos del gobierno y de la oposición, en cabeza del líder del partido Centro Democrático, se mostraban irreconciliables. No obstante, desde ambos puntos de vista, se le ofrecía al electorado visiones catastróficas del país. Para Uribe Vélez, la aprobación de los acuerdos pactados significaba "la entrega del país a guerrilla" y la implantación en Colombia del modelo "castro-chavista”. Para el gobierno, de ser rechazados los acuerdos en las urnas, a los colombianos les esperaba ya no una guerra en zonas apartadas de la geografía nacional, sino la "guerra urbana" que las FARC tenían preparada.

El 16 de junio de 2016, el presidente Juan Manuel Santos intervino en el Foro Económico Mundial que se realizó en la ciudad de Medellín. El discurso comenzó con una descripción general de los avances económicos que había tenido el país en el contexto de la desaceleración económica internacional, a los cuales aportaría significativamente la consolidación del proceso de paz:

[...] el otro gran punto, que nos va a ayudar muchísimo al desempeño económico lo mencionaba Felipe, es por supuesto lo más importante que tiene el país por delante y es lograr terminar un conflicto armado después de 50 años. (Santos, 2016a)

Para el presidente Santos, un factor determinante para el impulso de este proceso, había sido la política de seguridad del gobierno, cuya contundencia se había mantenido incluso durante el desarrollo de las negociaciones con las FARC, por eso el presidente no aceptó que su gobierno fuera tachado de "débil" y que se le considerara amigo de las FARC ${ }^{17}$ :

hemos sido implacables en esa parte militar, que es una condición también necesaria para lograr una solución negociada, negociando desde una posición de fuerza. A mí me dicen que yo soy muy cercano a las Farc, como una crítica que le hacen al proceso, yo realmente no

17. Durante el proceso de negociación de La Habana, y en el marco de la campaña del plebiscito por la paz, circularon distintos videos en las redes sociales en los cuales se hace aparecer -en una mezcla de información mentirosa y medias verdades sacadas de contexto - al presidente como alias "Santiago", supuesto guerrillero de las FARC (Juan Manuel santos alias (Santiago) bautizado así por Fidel Castro, 2016). 
entiendo ... [...] pero las Farc me decían a mí el verdugo, porque no había persona que le haya pegado más duro a ellos militarmente, porque han caído el número uno, el número dos, 63 de sus comandantes, y eso es lo que realmente nos ha permitido sentarnos a negociar, cuando ellos se dieron cuenta que por la vía de las armas nunca iban a poder llegar a tomarse el poder [...]. (Santos, 2016a)

En este sentido, indicó el presidente Juan Manuel Santos, el proceso de paz era el mecanismo idóneo para que las partes obtuvieran los mejores beneficios de una terminación no violenta del conflicto, que permitiera una salida "digna" para la insurgencia, de tal manera que esta guerrilla pudiera luchar por sus reivindicaciones en el marco de la confrontación política democrática:

[...] es muy importante, los militares sí que lo saben, que a la contraparte hay que permitirles una salida digna, construirles como quien dice un puente, unos dicen que de plata, otros dicen que de oro, pero salida digna, algo que fuera totalmente aceptable para el pueblo colombiano. (Santos, 2016a)

En esta misma intervención, el presidente procedió a explicar cada uno de los puntos acordados en La Habana hasta el momento, y los que estaban pendientes de discusión; además aclaró que "nada está acordado hasta que todo este acordado". Durante el desarrollo del discurso, el presidente habló de la posibilidad de un triunfo del No en el plebiscito, y en una clara apelación al miedo, describió las consecuencias nefastas que para los colombianos tendría la no refrendación de los acuerdos:

yo estoy seguro que la inmensa mayoría de los colombianos van a votar a favor del plebiscito porque se ha querido decir, no, es que si el plebiscito se niega vamos a poder negociar un acuerdo mejor. No, no se equivoquen. Si el plebiscito no se aprueba volvemos a la guerra, así de sencillo, no es que vamos a volver a la mesa de negociación, volvemos a la guerra, esa es la verdad. Porque han querido decir, que voten no porque vamos a darles un poco más de años de cárcel a los culpables de los crímenes atroces o que vamos a mejorar esta negociación. No, la negociación es integral, es un paquete, como cualquier negociación hay cosas que uno tiene que transar, por eso Felipe decía justicia, algo de justicia transaccional dentro de la justicia transicional. Y lo que logramos es un magnifico equilibrio, creo yo que no va a permitir como país dejar atrás ese capítulo horroroso de una guerra de cincuenta años [...] como sé que si no hay acuerdos volvemos a la guerra porque tenemos información amplísima que ellos están preparados para volver a la guerra y a la guerra urbana, que es mucho más demoledora que la guerra rural. Eso es una realidad, lo sé y por eso es tan importante que lleguemos a un acuerdo. (Santos, 2016a)

No obstante, las críticas que suscitó la alocución presidencial en Medellín, el argumento fue reiterado por los distintos voceros del gobierno nacional en los espacios 
de socialización de los contenidos de los acuerdos ${ }^{18}$. Es claro que, a estas alturas del debate, y de cara a la jornada electoral que se avecinaba, el gobierno echó mano de las emociones, especialmente del miedo, al proyectar un panorama oscuro en materia de seguridad y convivencia de no aprobarse los acuerdos de paz suscritos en La Habana.

En una intervención del 18 de julio de 2016, y en respuesta a la aprobación por la Corte Constitucional del plebiscito como mecanismos de refrendación de los acuerdos de paz alcanzados entre el gobierno nacional y las FARC, el presidente Santos pareció aligerar las consecuencias fatalistas de una posible victoria del No:

la Corte Constitucional dio su aprobación para que los ciudadanos podamos decidir en las urnas sobre el futuro de la paz. [...]

[...] ¿Queremos acabar con el más largo, el más cruel y el último conflicto armado de todo el hemisferio?, frente a estas preguntas, sabiendo lo que está en juego no podemos hacernos a un lado y dejar que la decisión la tomen otros [...]

[...] el objetivo es claro, terminar un conflicto cruel y doloroso que ha durado demasiados años y que ha producido demasiadas víctimas, demasiado sufrimiento, lo que queremos los colombianos es que no haya más víctimas, que podamos vivir sin miedo, con tranquilidad [...]. (Santos, 2016b)

El 26 de agosto de 2016, Uribe Vélez se pronunció sobre los acuerdos logrados entre las FARC y el gobierno nacional. Es de amplio conocimiento la poca responsabilidad del expresidente en el uso de la "palabra pública" (López de la Roche, 2014). En esta ocasión, y con motivo del acuerdo logrado, afirmó que el gobierno, mediante la negociación con las FARC, no sólo legitimó a esta guerrilla revistiéndola de una dimensión salvadora -como los justicieros buenos que luchan contra una feroz dictadura-, sino que equiparó la democracia colombiana con las peores dictaduras del Cono Sur, y a las fuerzas armadas legítimamente constituidas con la guerrilla de las FARC:

el gobierno ha utilizado este proceso para estimular el descrédito de nuestra democracia ante propios y ante la comunidad internacional. La democracia más extensa y menos interrumpida de América Latina, que ha superado todas imperfecciones sin claudicar ante el terrorismo queda igual a dictaduras y el narco terrorismo de las FARC como una legitima insurgencia de aquellas que enfrentaron a esas dictaduras. Nuestras fuerzas armadas, ejemplares en su espíritu democrático son igualadas al terrorismo, sometidas a su tribunal, condenadas a aceptar delitos no cometidos para evitar la cárcel y engañadas por la mentira oficial que les niega alternativas institucionales de alivio judicial. (Uribe Vélez, 2016)

18. Véase las posteriores intervenciones de Humberto de la Calle (Cosoy, 2016). 
De igual manera, Uribe Vélez acudió a la estrategia del miedo y la indignación, al asociar el acuerdo pactado con la implantación en el país del modelo "castro-chavista":

el gobierno disimula su indiferencia frente a los anhelos populares con un acuerdo de demagogia agrarista que busca la colectivización del campo y la destrucción del agro productivo. Así empezaron Castro y Chávez, dejaron a sus pueblos sin comida, después destruyeron la industria, la economía toda, ahuyentaron a los empresarios y arruinaron a los trabajadores, los ciudadanos honestos del campo rechazan la expropiación de sus tierras, reclaman condiciones para hacerlas producir. (Uribe Vélez, 2016)

En el discurso, el expresidente Uribe Vélez promovió la desconfianza con los acuerdos y se adelantó a vaticinar su fracaso al conjeturar que la guerrilla no dejaría las armas - las reemplazaría-, no renunciaría a la violencia como forma de acción política, combinaría política y guerra como había procedido en el pasado, y no abandonaría sus actividades ilícitas. El expresidente insistió en que la única solución viable era el sometimiento de la FARC a la justicia ordinaria y su reclusión en los centros penitenciarios, en aplicación del castigo justo conforme a la justicia retributiva ${ }^{19}$ :

[...] combinaron la política con la violencia, una de las causas del exterminio de la Unión Patriótica [...] con su dinero las FARC podrán reemplazar todas las armas que entregue, en la política creará una distorsión para comprar votos, superior a la mermelada corrupta del gobierno [...] el castigo justo ayuda a disuadir las intenciones criminales presentes y futuras que se den en la comunidad en general y no puede considerarse solamente en función de que sirva o sea inútil para corregir al delincuente castigado. (Uribe Vélez, 2016)

\section{Los opuestos continúan vigentes, la defensa de la paz y la oposición al régimen "castro-chavista"}

Un sistema democrático como el colombiano -constitucionalmente basado en el respeto de la dignidad humana, en el pluralismo - implica para los partidos, movimientos políticos y sociales que compiten por el poder una serie de compromisos que se deben

19. Como lo manifiesta Gutiérrez Sanín (2018), el uribismo durante sus ocho años de gobierno y para el período de negociación, aprobación e implementación de los acuerdos de paz con las FARC, ha entablado un discurso que pretende exacerbar los sentimientos de odio y miedo hacia este grupo guerrillero: "El uribismo tiene una base inorgánica pero muy enfurecida, radicalizada, llena de odios, que la cúpula ha alimentado meticulosamente". Buscando con ello evitar la implementación de cualquier proceso de justicia transicional con los grupos insurgentes, abogando por las políticas de exterminio o sometimiento a la justicia ordinaria. 
materializar en una práctica política cada vez más democrática ${ }^{20}$. Entre estos compromisos, Habermas $(2010$; 2014) resalta como mínimos una comunicación basada en la sinceridad entre las partes, donde no se oculte o se distorsione información, y en el peor de los casos, no se manipulen los procesos políticos para la satisfacción de intereses que no se declaran públicamente. En este orden de ideas, el artículo 20 de la Constitución Política de 1991, enuncia como derecho civil, con grandes implicaciones políticas y éticas la libertad de expresión:

Se garantiza a toda persona la libertad de expresar y difundir su pensamiento y opiniones, la de informar y recibir información veraz e imparcial, y la de fundar medios masivos de comunicación. Estos son libres y tienen responsabilidad social. Se garantiza el derecho a la rectificación en condiciones de equidad. No habrá censura. (Constitución Política de Colombia, 1991, énfasis de los autores)

Ahora bien, como se sostuvo en apartados anteriores, la idea de una comunicación racional es un componente fundamental del modelo democrático liberal ${ }^{21}$, no obstante, con el ingreso de las masas al espacio público, producto de la universalización del sufragio, han ganado terreno los componentes no racionales de la política como forma de movilizar y aglutinar a millones de votantes. Recordemos que ya Le Bon (1978) y Michels (2008) ${ }^{22}$ en sus obras -Psicología de las Multitudes y Los Partidos Políticos, obras pesimistas acerca de las promesas de la democracia-, publicadas a principios del siglo $\mathrm{XX}$, habían advertido sobre la existencia de un "comportamiento colectivo" distinto al individual. Para estos autores, las masas son "emocionales", "fácilmente impresionables" e "infantiles". Mostraron con crudeza la necesidad de liderazgo de las masas y lo fácil que resulta para los líderes manipular sus emociones como forma de aglutinar a un electorado disperso, que ya no se asocia en razón a la pertenencia a una clase social o a un partido político, sino en torno a un líder fuerte, que todo lo sabe, que conoce sus necesidades, piensa y actúa por ellas.

Así, durante la corta campaña del plebiscito por la paz, tanto los promotores del Sí como los del No recurrieron al uso de las emociones más que de las razones para

20. Al respecto, resultan pertinentes las observaciones de Habermas (2010; 2014), en el sentido de indicar que el democrático es un sistema abierto que por sus propios elementos participativos, deliberativos y pluralistas permiten caracterizarlo como un sistema siempre inacabado, en permanente evolución.

21. Recordemos con Manin (1998), que dos de las instituciones clásicas del modelo representativo son "la toma de decisiones mediante la discusión" y "la libertad de la opinión pública".

22. Para algunos estudiosos de estas obras y del período, Le Bon y Michels son pensadores conservadores y para otros inclusos precursores del Fascismo. 
persuadir a los votantes ${ }^{23}$. Pero quienes más lejos avanzaron por la senda de la manipulación de las emociones, o si se quiere, para expresarlo en un término que se ha vuelto de uso corriente en el lenguaje de los medios en los últimos dos años, los que más avanzaron por el camino de la "posverdad" ${ }^{24}$ fueron los promotores del No. Al respecto, son categóricas las declaraciones del gerente de la campaña del equipo nacional promotor del No, Juan Carlos Vélez Uribe, pocos días después del triunfo electoral conseguido por esos grupos políticos. En entrevista con el diario La República, que fue ampliamente difundida por los principales medios de comunicación del país, Vélez describió la estrategia de campaña de los promotores del No:

Pregunta: la campaña del Sí fue basada en la esperanza de un nuevo país, ¿cuál fue el mensaje de ustedes?

$\mathrm{R}$ de J.C.V/La indignación. Estábamos buscando que la gente saliera a votar verraca.

Más adelante insiste:

Pregunta: ¿Cómo fue la estrategia?

R de J.C.V/ [...] Unos estrategas de Panamá y Brasil nos dijeron que la estrategia era dejar de explicar los acuerdos para centrar el mensaje en la indignación. En emisoras de estratos medios y altos nos basamos en la no impunidad, la elegibilidad y la reforma tributaria, mientras en las emisoras de estratos bajos nos enfocamos en subsidios. En cuanto al segmento en cada región utilizamos sus respectivos acentos. En la Costa individualizamos el mensaje de que nos íbamos a convertir en Venezuela. (Ramírez Prado, 2016, énfasis de los autores)

Las declaraciones del gerente de la campaña del No dejan al descubierto la debilidad del proceso deliberativo democrático y el empobrecimiento de la esfera pública en la democracia colombiana de los últimos años. En un momento crucial para Colombia, la refrendación de los acuerdos de paz con el grupo armado de izquierda de mayor capacidad militar -y por tanto con mayor capacidad de infligir daño en términos de vidas y recursos, pero también de menoscabo de las instituciones democráticas- que haya conocido el país en la historia reciente, el diálogo racional y la búsqueda de la verdad

23. Se puede argumentar también que el gobierno tuvo una posición de poder privilegiada para promover, con recursos públicos, la campaña del Sí en el plebiscito por la paz. Aunque la directriz gubernamental hablaba de que podrán usarse recursos públicos para promover tanto el Sí como el No, y de esta forma generar igualdad entre los grupos en contienda, es claro que desde el gobierno se promovía el Sí (Restrepo, 2016).

24. El término "posverdad" alude a una realidad del discurso político contemporáneo donde "los hechos objetivos son menos influyentes en la opinión pública que las emociones y las creencias personales" (Rubio Hancock, 2016). 
son desplazados por las emociones, principalmente la indagación y el miedo ${ }^{25}$, emociones fáciles de movilizar en el contexto de una sociedad como la colombiana, cansada de la violencia guerrillera y que asistió durante ocho años de gobierno de Uribe a la construcción exitosa de un sentimiento de "nacionalismo antifariano", como bien lo designa Fabio López de la Roche. Los componentes del acuerdo: el desarrollo rural, la apertura a la participación política, los mecanismos eficaces de sustitución de cultivos de uso ilícito y los derechos de las víctimas no constituyeron el eje central del debate público ${ }^{26}$.

\section{Conclusiones}

El presidente Juan Manuel Santos - aunque tenía otras opciones jurídicas-, optó por el plebiscito como vía para refrendar los acuerdos negociados con las FARC en La Habana, tal vez para dotarlos de la legitimidad suficiente que facilitara su implementación ${ }^{27}$ o por los escasos recursos de poder con que contó para gestionar una iniciativa política de esta envergadura, dados los bajos niveles de popularidad con que contó a finales de su primer mandato y sobre todo en el segundo gobierno (Popularidad de Juan Manuel Santos cae al 21\%, 2013).

Una vez despejado el camino del plebiscito, el gobierno emprendió una campaña desde el Ejecutivo, con presupuesto público, que si bien no logró despertar las emociones suficientes alrededor de la paz que le garantizaran un triunfo contundente al Sí

25. Pero también la verdad es desalojada de debate público. Al respecto es importante remitir al lector al link de Youtube sobre la campaña del NO, de las iglesias cristiana y de la oposición: https://www.youtube.com/ watch?v=hSySHeMFIVU

Tuvimos la oportunidad de conocer apartes de la información contenida en el link gracias a la generosidad de Rubén Darío León Pineda, estudiante de Doctorado en Ciencias Políticas y Sociales de la Universidad Nacional Autónoma de México, quien presentó la ponencia "Marco Jurídico para la paz, un conflicto político entre palomas armadas y halcones sin nido" en el del 4 Congreso Latinoamericano y Caribeño de Ciencias Sociales que se celebró en la sede de FLACSO España en la ciudad de Salamanca, los días 17, 18 y 19 de julio de 2017, en el marco del panel "Estrategias de los líderes políticos en Colombia. Las disyuntivas confrontaciónnegociación, clientelismo-ideología, y participación-inmovilismo”.

26. Como lo indica Uprimny (2016), después de revelarse los resultados del plebiscito por la paz, "[...] los del Sí no tenían plan B pero los del NO no tenían plan A [...]”. Situación que develo frente al gobierno nacional, la confianza que este tenía sobre la victoria del Sí; y frente a los promotores del No, la ausencia de un programa de propuestas concretas para modificar los acuerdos de paz, que fuera más allá de la arenga constante de simple sometimiento a la justicia ordinaria por parte de la guerrilla de las FARC, su oposición no tiene pretensiones dialógicas constructivas.

27. "La principal garantía para las Farc del cumplimiento del Acuerdo, es la legitimidad política del Acuerdo. Que las Farc cumplan. Con el M-19 las garantías jurídicas eran débiles pero hubo legitimidad del acuerdo, y la sociedad ha cumplido" (Uprimny, 2016). 
en el plebiscito ${ }^{28}$, dejó al descubierto las ventajas del poder presidencial y a la postre molestó a un sector de la opinión que observó cómo la oposición estaba en condiciones desfavorables no solo en términos de acceso a recursos públicos, sino de visibilidad en los medios de comunicación -la prensa nacional, los canales de televisión, con excepción de noticias RCN televisión, bajo la dirección de Claudia Gurisatti y NTN 24 horas-.

De otro lado, los promotores del No - sectores del partido Conservador, grupos cristianos y el partido Centro Democrático - resultaron eficaces a la hora de movilizar el miedo que existe en un sector importante del electorado a las FARC y a su proyecto político. Miedo que un líder carismático como Álvaro Uribe Vélez -figura que aglutina distintos sectores políticos y sociales- ha sabido alimentar, primero desde la posición de presidente de la República -posición de poder por excelencia, más en un régimen presidencialista como el colombiano-, durante ocho años de gobierno y luego como senador del partido Centro Democrático, que ha desarrollado una férrea oposición al gobierno y al proceso de paz con las FARC.

El gobierno de Juan Manuel Santos llegó al poder gracias a la "bendición" de su predecesor, pero como hombre de poder, proveniente de la entraña de la élite colombiana, y tal vez convencido de que las circunstancias ofrecían la oportunidad de indagar en otras alternativas políticas - distintas únicamente a la confrontación militar-, pronto se demarcó de su mentor e inició acercamientos con las FARC, tendientes a indagar las posibilidades de una negociación que pusiera fin al largo enfrentamiento armado. Rápidamente, el gobierno Santos convierte el proceso de paz en su proyecto bandera. Tal vez por los efectos del discurso uribista, o porque el gobierno no supo comunicar su propuesta, o no logró suscitar las emociones suficientes, la oferta de la paz se topará con bajos niveles de aceptación y en lugar de procurarle réditos políticos al gobierno Santos, lo hizo aparecer como "débil" ante los ojos de un sector importante del electorado. Pero como bien han argumentado distintos estudiosos del régimen democrático, la incertidumbre es una de las características de esta forma de gobierno. Tanto los promotores del Sí como los del No, enfrentaron los resultados del plebiscito sin una propuesta alternativa. Pareciera que ni el gobierno contaba con la posibilidad de perder ni los promotores del No con la posibilidad de un triunfo.

28. Como lo indicara Basset, para algunos sectores de la sociedad colombiana, el rechazo de los acuerdos de paz y su implementación, estuvo dada por la creencia que este sólo beneficiaría a las zonas afectadas por el conflicto, y en tal medida su aprobación sólo conllevaría la exclusión de estos del proceso de redistribución social de las políticas públicas del Estado: "[...] Muy probablemente, los habitantes de estos espacios sintieron que la atención del Gobierno se centraría exclusivamente sobre las zonas directamente afectadas por el conflicto y que, por tanto, iban a ser, de algún modo, los olvidados de la paz, a pesar de sufrir muchos efectos colaterales del conflicto" (2018, p. 263). 
Los acontecimientos anteriores al plebiscito y los sucesos posteriores al 2 de octubre de 2016 mostraron la poca imaginación tanto de los líderes del No como de los del Sí. Para los del No la oposición casi irracional a los acuerdos fue su única propuesta. El gobierno, desde una posición de poder privilegiada, menospreció la capacidad movilizadora y organizativa de la oposición y tuvo desde el principio una actitud triunfalista y al parecer no consideró en ningún momento un plan B en caso de ser derrotado en las urnas.

La jornada electoral del 2 de octubre permitió observar la "fortaleza de la democracia colombiana". No asistimos al escenario de "guerra urbana" que pronosticó el presidente Santos en caso de que los colombianos no refrendaran lo pactado, tampoco se impuso el modelo "castro-chavista" con el que el uribismo y sectores afines movilizaron a las urnas a numerosos votantes, no obstante, el fantasma del "castro-chavismo" continúa presente en el discurso del expresidente Álvaro Uribe Vélez y será agitado en las próximas elecciones presidenciales del año 2018. Pero también hay que decirlo, frente a los resultados del plebiscito, la guerrilla de las FARC mostró coherencia, fiel a la promesa de no volver a la guerra si ganaba el No, esa guerrilla no se levantó de la mesa mientras el gobierno y la oposición buscaban, sin resultados, un acuerdo que sacara del limbo al proceso de paz, luego de las elecciones del 2 de octubre.

\section{Referencias}

Alcántara Saéz, M. (06 de diciembre de 2017). Permanecer, volver: políticos numerarios. El País, recuperado de https:/elpais.com/elpais/2017/12/04/opinion/1512401243_042244.html

Álvaro Uribe critica los diálogos de paz que adelanta el gobierno colombiano con las FARC. (29 de agosto de 2012). NTN24, recuperado de https://www.youtube.com/ watch?v=LC9j566dJbE

Basset, Y. (2018). Claves del rechazo del plebiscito para la paz en Colombia. Estudios Políticos 52, 241-265. http://doi.org/10.17533/udea.espo.n52a12

Bobbio, N. (2005). El futuro de la democracia. México: Fondo de Cultura Económica.

Botero Uribe, D. (2001). El poder de la filosofía y la filosofía del poder. Tomo I. Bogotá: Editorial Universidad Nacional de Colombia.

Cardona Zuleta, L. M. (2016). La culebra sigue viva: miedo y política. El ascenso de Álvaro Uribe al poder presidencial en Colombia (2002-2010). Medellín: Editorial Universidad Nacional de Colombia.

Colprensa. (12 de febrero de 2015). "Tememos que Colombia tome ese camino castrochavista": Uribe. El Colombiano, recuperado de http://www.elcolombiano.com/colombia/ politica/tememos-que-colombia-tome-ese-camino-castrochavista--uribe-BY1265939 
Congreso de la República de Colombia. Acto Legislativo 01 de 2012.

Congreso de la República de Colombia. Ley N 1448 de 2011.

Congreso de la República de Colombia. Ley N 1745 de 2014.

Congreso de la República de Colombia. Ley N 1806 de 2016. Recuperado de http:// es.presidencia.gov.co/normativa/normativa/LEY\%201806\%20DEL\%2024\%20DE\%20 AGOSTO\%20DE\%202016.pdf

Constitución Política de Colombia de 1991.

Corte Constitucional. Sentencia C-379 del 18 de julio de 2016, Magistrado Ponente Dr. Luis Ernesto Vargas Silva.

Cosoy, N. (14 de septiembre de 2016). Humberto de la Calle: el primer paso es que los colombianos entiendan que "no hay violencia buena". BBC Mundo, recuperado de http://www.bbc.com/mundo/noticias-america-latina-37357984

Cronología del proceso de paz. (24 de enero de 2014). Caracol Radio, recuperado de http://caracol.com.co/radio/2013/10/18/nacional/1382097060_997459.html

Fermín T., Eudis F. (2012). La denuncia colombiana en la OEA: Presencia de grupos narcoterroristas en el territorio venezolano. Reflexión Política, 14 (28), 52-67. Recuperado de http://www.redalyc.org/pdf/110/11025028005.pdf

Ferrajoli, L. (2009). Derecho y razón. Teoría del garantismo penal. Madrid: Editorial Trotta.

Gómez Giraldo, J. C. (2005). Del régimen de comunicación política del Presidente de Colombia Álvaro Uribe Vélez. Palabra Clave, 8(2), 63-92. Recuperado de http://palabraclave.unisabana.edu.co/index.php/palabraclave/article/view/1461/1629

Gutiérrez Sanín, F. (26 de enero de 2018). Uribe es el único político con capacidad de coordinar los intereses de las élites legales e ilegales. Las Silla Académica, recuperado de http://lasillavacia.com/silla-academica/uribe-es-el-unico-politico-con-capacidad-de-coordinar-los-intereses-de-las-elites

Habermas, J. (2010). Facticidad y validez. Madrid: Editorial Trotta.

Habermas, J. (2014). Teoría de la acción comunicativa. Tomos I y II. Madrid: Editorial Trotta. Isaza Giraldo, M. (11 de marzo de 2016). Plebiscito no puede ser vinculante para avalar acuerdo final: Fiscal. El Colombiano, recuperado de http://www.elcolombiano.com/ colombia/paz-y-derechos-humanos/plebiscito-no-puede-ser-vinculante-para-aprobacion-del-acuerdo-final--fiscal-BA3736838

Juan Manuel santos alias (Santiago) bautizado así por Fidel Castro. (25 de febrero de 2016). Recuperado de https://www.youtube.com/watch?v=WaULkXqWvU0

Le pido al Gobierno que diga si es verdad que están negociando un proceso de paz en Cuba: Álvaro Uribe. (21 de agosto de 2012). Caracol Radio, recuperado de http://caracol.com.co/radio/2012/08/20/nacional/1345484280_747175.html 
Le Bon, G. (1978). Psicología de las multitudes. Buenos Aires: Editorial Albatros.

López de la Roche, F. (2014). Las ficciones del poder. Patriotismo, medios de comunicación y reorientación afectiva de los colombianos bajo Uribe Vélez (2002-2010). Bogotá: Biblioteca Iepri.

Michels, R. (2008). Los partidos políticos: un estudio sociológico de las tendencias oligárquicas de la democracia moderna. Vol. 1 Buenos Aires: Editorial Amorrortu.

Manin, B. (1997). Los principios del gobierno representativo. Madrid: Alianza Editorial.

Morelo, D. (05 de octubre de 2016). Así es el país que votó No. Las Silla Vacía, recuperado de http://lasillavacia.com/hagame-el-cruce/asi-es-el-pais-que-voto-no-58201

Palacio, A. y Quintero, F. (21 de febrero de 2002). Secuestro aéreo, puntillazo final. El Tiempo, recuperado de http://www.eltiempo.com/archivo/documento/MAM-1308661/ Popularidad de Juan Manuel Santos cae al 21\%. (04 de septiembre de 2013). Revista Semana, recuperado de http://www.semana.com/nacion/articulo/popularidad-del-Presidente-juan-manuel-santos-cae-al-21/356453-3

Presidencia de la República de Colombia. Decreto 1391 de 2016.

Principales propuestas de Juan Manuel Santos. (19 de junio de 2010). Caracol Radio, recuperado de http://caracol.com.co/radio/2010/06/19/nacional/1276959600_315420.html Ramírez Prado, J. (04 de octubre de 2016). El No ha sido la campaña más barata y más efectiva de la historia. Asuntos legales, recuperado de https://www.asuntoslegales.com.co/ actualidad/el-no-ha-sido-la-campana-mas-barata-y-mas-efectiva-de-la-historia-2427891

Redacción Colombia.com. (20 de junio de 2010). Resultados Elecciones 2010. Colombia. com, recuperado de http://www.colombia.com/especiales/elecciones_2010/

Redacción El Heraldo.co. (17 de junio de 2016). "Farc están preparadas para guerra urbana si se cae proceso2: Santos. El Heraldo, recuperado de https://www.elheraldo.co/colombia/farc-estan-preparadas-para-guerra-urbana-si-se-cae-proceso-santos-266791

Redacción El País. (30 de julio de 2010). Presidente Álvaro Uribe termina su gestión con $80 \%$ de aprobación. El País, recuperado de http://www.elpais.com.co/colombia/Presidente-alvaro-uribe-termina-su-gestion-con-80-de-aprobacion.html

Redacción El Tiempo. (23 de noviembre de 2010). El fracaso de los diálogos de paz en El Caguán. El Tiempo, recuperado de http://www.eltiempo.com/archivo/documento/ CMS-8430440

Redacción El Tiempo. (07 de noviembre de 2015). Por qué la apuesta por el plebiscito para refrendar la paz. El Tiempo, recuperado de http://www.eltiempo.com/archivo/ documento/CMS-16424318

Redacción Paz. (28 de junio de 2016). Farc sostienen que si pierden el plebiscito no volverán a la guerra. El Espectador, recuperado de https://www.elespectador.com/ node/640303 
Redacción Política. (22 de agosto de 2013). Santos presentará al Congreso ley para refrendar acuerdo con las Farc. El Espectador, recuperado de https://www.elespectador.com/noticias/politica/santos-presentara-al-congreso-ley-refrendar-acuerdo-far-articulo-441781

Redacción Semana. (18 de septiembre de 2005). Seguridad democrática. Revista Semana, recuperado de http://www.semana.com/on-line/articulo/seguridad-democrati$\mathrm{ca} / 67637-3$

Redacción Semana. (29 de agosto de 2016). Congreso da visto bueno al plebiscito. Revista Semana, recuperado de http://www.semana.com/nacion/articulo/plebiscito-por-la-paz-congreso-decide-permitir-la-refrendacion/491676

Registraduría Nacional del Estado Civil. (2016). Preconteo plebiscito. Recuperado de https://elecciones.registraduria.gov.co/pre_plebis_2016/99PL/DPLZZZZZZZZZZZZZZZZZ_L1.htm

Restrepo S., C. O. (05 de septiembre de 2016). Funcionarios podrán usar recursos públicos en campaña de plebiscito. El Colombiano, recuperado de http://www.elcolombiano.com/colombia/acuerdos-de-gobierno-y-farc/funcionarios-podran-usar-recursos-publicos-en-campana-de-plebiscito-ML4926493/

Robin, C. (2009). Miedo. Historia de una idea política. México: Fondo de Cultura Económica.

Rubio Hancock, J. (16 de noviembre de 2016). El Diccionario de Oxford dedica su palabra del año, posverdad, a Trump y al Brexit. El País, recuperado de https://verne. elpais.com/verne/2016/11/16/articulo/1479308638_931299.html

Santos, J. M. (4 de septiembre de 2012). Alocución del Presidente de la República, Juan Manuel Santos sobre el "Acuerdo General para la Terminación del Conflicto". Presidencia de la República de Colombia, recuperado de http://wsp.presidencia.gov.co/Prensa/2012/ Septiembre/Paginas/20120904_01.aspx

Santos, J. M. (16 y 17 de junio de 2016a). Securing Peace in Colombia. World Economic Forum on Latin America, recuperado de https://www.weforum.org/events/ world-economic-forum-on-latin-america-2016/sessions/securing-peace-in-colombia Santos, J. M. (18 de julio de 2016b). Alocución del Presidente Juan Manuel Santos. Presidencia de la República de Colombia, recuperado de https://www.youtube.com/watch?$\mathrm{v}=\mathrm{e} 3 \mathrm{YBiUzik9o}$

Uprimny, R. (04 de noviembre de 2016). "Los del Sí no tenían plan B pero los del No no tenían plan A”. Las Silla Llena, recuperado de http://lasillavacia.com/silla-llena/red-lider/historia/los-del-si-no-tenian-plan-b-pero-los-del-no-no-tenian-plan-rodrigo

Uribe Vélez, A. (26 de agosto de 2016). Esto fue lo que dijo Álvaro Uribe Vélez sobre lo pactado en La Habana. Opinión Caribe, recuperado de https://www.youtube.com/ watch?v=Y-GGa9H9uhI 
Wallace, A. (10 de junio de 2014). Santos y el uribismo: un divorcio que retrata a la política colombiana. BBC Mundo, recuperado de http://www.bbc.com/mundo/noticias/2014/06/140610_colombia_santos_uribismo_analisis_aw

Yannuzzi, M. de A. (2007). Democracia y sociedad de masas. La transformación del pensamiento político moderno. Rosario: HomoSapiens.

\section{Cómo citar}

Cardona Zuleta, L. M. y Londoño Álvarez, C. A. (2018). La retórica del miedo como estrategia política. El plebiscito por la paz en Colombia. FORUM. Revista Departamento Ciencia Política, 14, 43-68. 